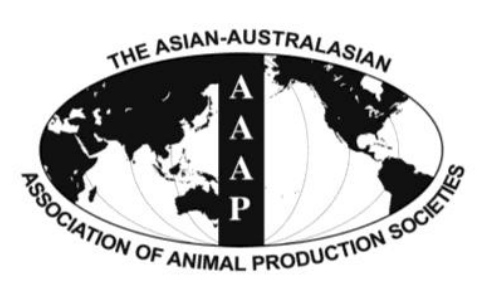

Open Access

Asian Australas. J. Anim. Sci.

Vol. 27, No. 2 : 290-301 February 2014

http://dx.doi.org/10.5713/ajas.2013.13261

www.ajas.info

pISSN 101 1-2367 elSSN 1976-5517

\title{
Multicarbohydrase Enzymes for Non-ruminants
}

\author{
H. V. Masey O'Neill*, J. A. Smith, and M. R. Bedford \\ AB Vista Feed Ingredients, Marlborough, SN8 4AN, UK
}

\begin{abstract}
The first purpose of this review is to outline some of the background information necessary to understand the mechanisms of action of fibre-degrading enzymes in non-ruminants. Secondly, the well-known and understood mechanisms are described, i) eliminating the nutrient encapsulating effect of the cell wall and ii) ameliorating viscosity problems associated with certain Non Starch Polysaccharides, particularly arabinoxylans and $\beta$-glucans. A third, indirect mechanism is then discussed: the activity of such enzymes in producing prebiotic oligosaccharides and promoting beneficial cecal fermentation. The literature contains a wealth of information on various non starch polysaccharide degrading enzyme (NSPase) preparations and this review aims to conclude by discussing this body of work, with reference to the above mechanisms. It is suggested that the way in which multi- versus singlecomponent products are compared is often flawed and that some continuity should be employed in methods and terminology. (Key Words: Broiler, Enzyme, Glucanase, Non-starch Polysaccharide, Xylanase)
\end{abstract}

\section{INTRODUCTION}

Since the 1980's, there have been two paradigmatic shifts in enzyme use in the feed industry: the mass introduction of fibre-degrading enzymes followed by that of phytases. The use of phytases to release phosphorous (P) has been hugely successful, resulting in widespread commercial application. The effective use of enzymes to hydrolyse non-starch polysaccharides (NSP), however, has been the subject of much debate and it appears that there is no general consensus on which particular enzyme, or enzymes, result in the greatest benefits. This is in part due to the complexity of the potential substrates, which varies by cereal and diet formulation. Because of this, a growing body of literature advocating the use of multi-enzyme preparations has emerged, particularly of those with multicarbohydrase activities (e.g. Slominski, 2000). However, much of the information available on the use of multi-enzymes may be incomplete, with conclusions potentially with huge commercial significance - based on

\footnotetext{
* Corresponding Author: H. V. Masey O’Neill. Tel: +44-0-1672517-667, Fax: +44-0-1672-517-660, E-mail: Helen.maseyo'neill @abvista.com
}

Submitted May 12, 2013; Accepted Aug. 2, 2013; Revised Sept. 14, 2013 data obtained from experiments not adequately designed to support those conclusions. The aims of this paper are to present the arguments for using both single and multienzymes, describe current theories on mechanisms of action and critically analyse the rationale and experimental methods on which these arguments are based.

There are two long-standing mechanisms by which NSP- degrading enzymes (NSPases) are thought to improve performance, both of which involve reducing the antinutritive effect of NSP: i) eliminating the nutrient encapsulating effect of the cell wall and ii) ameliorating viscosity problems associated with certain NSPs, particularly arabinoxylans and $\beta$-glucans. First, the majority of the available energy in cereal grains comes from starch, however this is stored intracellularly, and is partly inaccessible to non-ruminants in the absence of exogenous enzyme supplementation as they have a limited endogenous ability to degrade plant cell wall material. Therefore, supplementation with enzymes capable of degrading cell wall polysaccharides may allow pancreatic enzymes access to nutrients trapped within the cell. An additional benefit is that cell wall degradation releases oligosaccharides or even mono-saccharides that could either be directly absorbed or degraded by the intestinal microflora to provide volatile fatty acids (VFAs) for the animal to utilize as energy. 
Second, soluble NSP may increase viscosity of digesta which has been shown to greatly inhibit nutrient uptake and potentially encourage pathogenic bacteria. By adding hydrolytic enzymes, the molecular weight of NSPs is reduced which reduces viscosity and associated problems.

Before any discussion of enzyme classes can take place, it is important to outline the different product categories on the market. To the authors' knowledge, there are no companies supplying purified enzyme proteins for use in animal feed. Therefore, all products will contain other material of some description, such as a carrier or byproducts of their manufacture. They are commonly produced by bacterial or fungal fermentation with bacilli being common for protease and amylase production (Schaeffer, 1969) and fungal species of Trichoderma or Aspergilli for cellulases and hemicellulases such as xylanase (Persson et al., 1991; Polizeli et al., 2005). In probably all cases, the final product will include some enzyme side activity. Generally, NSPase products fall into three categories. The first is single-component products which are likely advertised by their main component, for example, xylanase or $\beta$-glucanase. These will probably be produced by a microbial or fungal fermentation system where the production organism may or may not have other enzyme genes deleted. It is also possible to induce fungi to produce only xylanase without a cellulase side activity, for example (Polizeli et al., 2005). Either way, some limited activities may persist and so may some materials of the fermentation process. Such side activities may or may not be promoted by the manufacturer. However, in modern products the target activity is both over-expressed and may have been engineered to have characteristics such as thermostability which the side activities do not possess, rendering the product virtually a single-component product in a heat treated feed. The second category is blended products. Usually, these contain two or three distinct activities which are produced individually as above and blended. Therefore, they may have two or three primary activities which, individually, are subject to the same considerations as single-component products. The third category has been termed enzyme 'cocktails' and are the product of a single fermentation that produces a multitude of activities (in one commercial example, as many as 43 , Guais et al., 2008) which are unlikely to all be quality controlled or promoted by the manufacturer. Publications may only list two of the activities (Walsh et al., 2012) which is contrary to the suggestion that the full composition of the same product is important (Guais et al., 2008). Those side activities may or may not be beneficial and may be broader than NSPase; they may have amylolytic, proteolytic, lipolytic and phytolytic activity, for example. This creates a problem in that it is not possible to assign efficacy of such a product to any specific component of that product, declared and analysed or not.

In order for a detailed discussion of the above ideas to take place, an understanding of plant cell wall composition, and its variability amongst different feed ingredients, is necessary. It was recognized several decades ago that 'the great differences in chemical composition among the different foods is notable and one would therefore also expect great differences in the physical, biological and nutritional properties of the different DF [dietary fibre] sources' (Theander et al., 1989). This message remains relevant to date, and its importance shall become apparent throughout the course of this review. The typical composition of the plant cell wall is described, followed by a brief discussion of the differences in their levels between cereals most commonly included in poultry feed.

\section{PLANT CELL WALL COMPOSITION}

The plant cell wall consists largely of NSP that are traditionally classified into three groups: cellulose, hemicelluloses and pectins. However, the term hemicelluloses originally came into use as a result of mistaken identification; they were thought to be precursors of cellulose. Cellulose consists of hydrogen-bonded microfibrils, comprised of $\beta-1-4$-glucose chains, and is the most abundant organic macromolecule. Hemicelluloses are the subject of much of this review, and are in fact not easily defined. They include possibly the most significant polysaccharides when considering enzyme use: pentosans (in particular arabinoxylans) and $\beta$-glucans, as well as mannans, arabinans, galactans and xyloglucans. Some appear superficially similar to cellulose, though differ in that the constituent chains are branched, containing neutral backbone sugars that often form hydrogen bonds with cellulose. Pectins, or pectic polysaccharides, contain uronic acids (UA), and are defined as such (Theander et al., 1989; Somerville et al., 2004). These are generally found only in small quantities in cereal plants (Choct, 1997).

Beta-glucans are present in most cereals, though are particularly prevalent in barley and oats. They consist of linear chains of glucose monomers, joined, in varying proportions, by both $\beta-1-3$ and $\beta-1-4$ linkages. At a molecular level it appears that $\beta$-glucans are similar to cellulose; however, the presence of the $\beta-1-3$ linkages disrupts the uniform structure seen in cellulose which allows microfibrils to pack closely together (Burton and Fincher, 2009). Thus, $\beta$-glucans are more soluble than cellulose and due to their considerable length may form viscous solutions, which can lead to significant reductions in digestibility of nutrients. Similarly, soluble pentosans may lead to viscosity problems. The most common cereal pentosan is arabinoxylan, which makes up the majority of cell wall NSP in maize, wheat, rye and barley. It consists of 
a $\beta-1-4$ xylan backbone - the monomers being xylose - to which arabinose monomers commonly bind (Saulnier et al., 2012). Other substituents such as hexoses are common, and protein or phenolic side chains have been reported, though are present in much lower concentrations than arabinose residues. The $\mathrm{O} 2$ and $\mathrm{O} 3$ positions of xylosyl residues are the most likely binding sites for side chains or substituents, with most arabinose residues binding to O3 (Saulnier et al., 2012). Arabinoxylans bound to the cellulose cell wall tend to be insoluble in water; however those not bound can form highly viscous solutions. This is of particular importance in wheat and rye, where the soluble proportion of arabinoxylan is relatively large (Choct, 1997).

Other components in cereal cell walls are mannans, arabinans and galactans, which are also non-cellulosic polysaccharides. Mannans may be either glucomannans or galactomannans, both of which are hexosans. Glucomannans consist of glucose and mannose monomers with $\beta$-1-4 linkages, whereas galactomannans comprise a backbone of 1-4- $\beta$-linked mannose units with substitutions of $\alpha-1-6$ galactose. Arabinans are $\alpha-1-5$-linked chains of arabinose which may be branched at either the $\mathrm{O} 2$ or $\mathrm{O} 3$ atoms or at both, and galactans are chains of $\beta-1-4$ linked galactose units (there can occasionally be $\beta-1-6$ linkages as well). Arabinogalactans are polymers with a galactan backbone and arabinan side chains (Choct, 1997).

\section{AMELIORATING THE ANTI-NUTRITIVE EFFECT}

In the starchy endosperm of, wheat, for example, cell wall material may account for $7 \%$ of tissue (Saulnier et al., 2012). The abundance of the various cell wall components are shown for several cereals in Table 1. Wheat and rye have particularly high soluble arabinoxylan levels, and barley has high levels of soluble mixed-linked $\beta$-glucans. It is in these cereals that viscosity is likely to be the primary driver in a loss in performance and welfare problems (Antoniou and Marquardt, 1981; Annison and Choct, 1991).

The use of exogenous enzymes in poultry feeding was first suggested in the mid nineteen twenties. In 1925,
Hervey described dramatically improved Leghorn performance with the use of 'Protozyme'; $5 \%$ inclusion of the product decreased 20-week feed conversion from 5.85 to 4.93. In 1926, in Poultry Science, Clickner and Follwell described this product as having multiple activities, with the major activity appearing to be an amylase with a broad $\mathrm{pH}$ optimum. Hervey (1925) attributes the performance benefit to increased protein and starch digestibility, assumed to be brought on by direct digestion of those materials by the exogenous enzymes. Experiments in the 1950s and early 1960s by groups in Washington (Jensen et al., 1957; Fry et al., 1958) and Oregon (Arscott and Rose, 1960; Rose and Arscott, 1962) showed that adding an amylolytic enzyme preparation to barley-based broiler diets could reduce sticky droppings and improve growth, though the enzymes were ineffective in wheat based diets. Both groups suggest that when barley is added to the diet in place of corn, energy availability falls and the enzyme acts to recover this energy loss. They suggest simply that chicks do not possess enzymes for maximum digestibility of barley, although they state little about the specific substrate for the exogenous enzyme product. Later, the benefits of such an amylolytic product were attributed to a contaminating side activity endo- $\beta$-glucanase - which shortened soluble glucan chains, resulting in reductions in viscosity and improved nutrient digestibility (Burnett, 1966). Chesson (1987) suggested that this explained the lack of response in wheat, where soluble glucan is negligible. Significant work in the 1970s and 1980s characterised and described the negative effects of glucan in barley and the benefits of adding glucanase preparations to diets for broilers (Gohl et al., 1978; Hesselman et al., 1981; White et al., 1981; Hesselman et al., 1982; White et al., 1983). Concurrently, work showed the negative effects of rye on digestibility of various nutrients and animal performance (Moran et al., 1969; Macauliffe and McGinnis, 1971; Antoniou et al., 1981). This was attributed, similarly, to the viscosity induced by soluble pentosans (Marquardt et al., 1979; Antoniou et al., 1981) and as such attenuated by the specific use of pentosanases for broilers (Pettersson and Aman, 1988; Bedford et al.,

Table 1. Types and estimated levels of the major fibre constituents present in some cereal grains, \% dry matter (adapted from Choct, 1997)

\begin{tabular}{lllcccccc}
\hline Cereal & & $\mathrm{AX}^{1}$ & $\beta$-Glucan & Cellulose & Mannan & Galactan & UA $^{2}$ & Total \\
\hline \multirow{2}{*}{ Wheat } & Soluble & 1.8 & 0.4 & - & - & 0.2 & - & 2.4 \\
& Insoluble & 6.3 & 0.4 & 2.0 & - & 0.1 & 0.2 & 9.0 \\
Barley & Soluble & 0.8 & 3.6 & - & - & 0.1 & - & 4.5 \\
& Insoluble & 7.1 & 0.7 & 3.9 & 0.2 & 0.1 & 0.2 & 12.2 \\
\multirow{2}{*}{ Rye } & Soluble & 3.4 & 0.9 & - & 0.1 & 0.1 & 0.1 & 4.6 \\
& Insoluble & 5.5 & 1.1 & 1.5 & 0.2 & 0.2 & 0.1 & 8.6 \\
Corn & Soluble & 0.1 & - & - & - & - & - & 0.1 \\
& Insoluble & 5.1 & - & 2.0 & 0.2 & 0.6 & - & 8.0 \\
\hline
\end{tabular}

${ }^{1}$ Arabinoxylan (arabinose+xylose). ${ }^{2}$ Uronic acid. 
1991) and pigs (Thacker et al., 1991). The pentosans in rye and wheat are similar in structure and Australian work showed that the negative effects of adding extracted pentosans from wheat to broiler diets (Choct and Annison, 1990; Angkanaporn et al., 1994) could be overcome by inclusion of a pentosanase, subsequntly improving apparent metabolisable energy (AME) and nutrient digestibilities (Annison, 1992). Again, it is the soluble, viscous component that likely causes worsened performance (Annison, 1991).

Aside from the effect of reducing viscosity, it was also suggested that there is an accompanying benefit of liberating starch and proteins previously trapped within the cell wall (Hesselman and Aman, 1986). The identification of the true enzyme-substrate interaction leads to the realisation that the high arabinoxylan content in wheat could be targeted with xylanases, which were shown to improve performance in broiler chicks via the same mechanisms as $\beta$-glucanase in barley (Bedford and Classen, 1992). Supplementation of xylanase to corn based diets has also been shown to improve performance, again in broilers (Aftab, 2012), despite a small portion of soluble arabinoxylan, suggesting that mechanisms other than viscosity reduction are important. Similarly, it has been shown that xylanase can improve performance in low viscosity wheat in turkeys from 3 to 15 weeks (Persia et al., 2002). Even though none of the preparations used above were likely pure, the common thread was that the measured activity in all cases was xylanase in wheat and glucanase in barley based diets. Choct et al. (1999) added xylanase and protease to wheat based diets but did not discuss the value of the protease on the improvements seen, presumably because the main effect is attributable to xylanase.

Commercial enzymes described as xylanases are often blends or cocktails with xylanase as a main activity (Choct, 1999; Aftab, 2012). In many trials these enzymes are shown to be effective in improving performance (for example, in broilers, Silversides and Bedford, 1999). However, as far as the authors are aware, very few trials of such enzymes have been conducted and published with a control in place that is supplemented only with single component xylanase. One such paper, (Grootwassink et al., 1989), did suggest that purification of a crude pentosanase resulted in a loss of efficacy when fed to broilers but the purified product was less than $30 \%$ stable at $\mathrm{pH} 3$ and 2 whereas the crude product was greater than $70 \%$ stable. The poor performance of the purified product is therefore just as much likely due to loss in xylanase activity as it is to the benefit of ancillary enzymes. Therefore, there is no evidence determining whether the extra activities are beneficial, superfluous or even deleterious. Indeed, there are several trials showing that products that appear to be single component xylanases are capable of improving performance in both wheat (Masey O'Neill et al., 2012a) and maize based diets for broilers (Cowieson et al., 2010; Cengiz et al., 2012; Masey O'Neill et al., 2012b). In two of those experiments, a Trichoderma-reesei-produced xylanase was used (Econase XT, AB Vista Feed Ingredients, Marlborough, UK) and feed was pelleted (Cowieson et al., 2010; Masey O'Neill et al., 2012a). A typical analysis of this product is shown in Table 2. Side activities are low and not thermostable. Fungal production systems such as this are likely to have low carbohydrase, and even lower protease and other, side activities. Since the target activity (xylanase in this case) is so dominant in fungal as compared with bacterial-expressed products like these, and the remaining side activites are not thermotolerant, they are as close to monocomponent products as we are likely to get (Polizeli et al., 2005).

Another significant point is raised here: the nomenclature used in the literature is inconsistent and potentially misleading. On top of the above examples, in one trial, the terms xylanase, pentosanase and glycanase are used interchangeably to describe an enzyme with both xylanase and protease activity (Choct et al., 1999). Often, supposedly single component enzymes may actually have more than one activity, especially if not heat treated, and products advertised as blends of multi-carbohydrases may have many more activities than those declared (Cowan et al., 1999). Finally, in some cases, an enzyme that includes substantial protease activity is described as a multicarbohydrase (Józefiak et al., 2010). Greater care and clarification is needed to reduce the ambiguity currently

Table 2. Typical analysis of Econase XT, pre and post pellet at $95^{\circ} \mathrm{C}$ (J. Piironen, Personal communication)

\begin{tabular}{lccc}
\hline Sample & $\begin{array}{c}\text { Xylanase activity } \\
\left(\mathrm{BXU}^{1} / \mathrm{kg}\right)\end{array}$ & $\begin{array}{c}\text { Beta-Glucanase activity } \\
\left(\mathrm{BU}^{2} / \mathrm{kg}\right)\end{array}$ & $\begin{array}{c}\text { Cellulase activity } \\
\left(\mathrm{ECU}^{3} / \mathrm{kg}\right)\end{array}$ \\
\hline Meal post - mixing & $6,436,000$ & 489,300 & 67,270 \\
Pellet post pelleting at $95^{\circ} \mathrm{C}$ & $6,313,000$ & 16,930 & 3,429 \\
Recovery (\%) & 98.1 & 3.5 & 5.1 \\
\hline
\end{tabular}

${ }^{1}$ Birch xylanase unit, defined as the amount of enzyme producing one nmole of reducing sugars as xylose from birch xylan in one second under the assay conditions $\left(\right.$ at $\left.50^{\circ} \mathrm{C}, \mathrm{pH} 5.3\right)$.

${ }^{2}$ Endo-1,4- $\beta$-glucanase unit, defined as the amount of enzyme producing one nmole of reducing sugars as glucose from barley $\beta$-glucan in one second under the assay conditions $\left(\right.$ at $\left.50^{\circ} \mathrm{C}, \mathrm{pH} 4.8\right)$.

${ }^{3}$ Endo-cellulase unit, defined as the amount of enzyme producing one nmole of reducing sugars as glucose from hydroxyethyl cellulose in one second under the assay conditions $\left(\right.$ at $\left.50^{\circ} \mathrm{C}, \mathrm{pH} 4.8\right)$. 
associated with enzyme description. All activities should be listed in scientific publications, as should their recovery in pelleted feed. Journal editors should be aware of this as a potential issue.

Some commercial enzymes are purported to contain exo-acting components that release monosaccharides from NSPs, subsequently used for energy (Guais et al., 2008). Chesson (1987) and Schutte (1990) highlight some theoretical problems with total saccharification of cell wall polysaccharides. Relatively few bonds must be cleaved by endo-acting enzymes to rapidly degrade NSP into oligosaccharides. The release of a substantial proportion of monosaccharides by exo-acting enzymes, however, requires hydrolysis of a much larger number of glycosidic linkages, which requires greater energy investment. Furthermore, it is often assumed that all breakdown products of such extensive hydrolysis are useful to the animal but in fact they may even be harmful. Schutte (1990), showed that even relatively low levels of dietary xylose and arabinose $(2.5 \%)$ had a negative effect on bird performance. As percentage inclusion was increased, the AME value of the pentoses decreased, probably as a result of decreased absorption capacity and the energy cost of increased excretion. It is clear from this that complete degradation of pentosans, and probably some other NSPs, by exo-acting enzymes, far from making useful sugars available, may be detrimental to performance. Given the widespread use of wheat based diets, this is very significant. Perhaps more important though is the point that can be inferred; it cannot be assumed that hydrolysis of all cell wall components is beneficial. This must be recognized, as the extent of NSP degradation is often considered to be a marker for enzyme efficacy, particularly in in vitro trials (Meng et al., 2005). Furthermore, oligosaccharides produced from partial hydrolysis of NSP are in fact implicated in optimum intestinal tract health, and this is discussed below. Therefore, the products of hydrolysis should be carefully considered when choosing an NSP degrading enzyme product, not just the extent of hydrolysis. As such, it may even be that the extent of hydrolysis should be tempered for optimum efficacy. Furthermore, there is some evidence in the literature that the response to increasing dose of NSP enzymes is non-linear; that is the response does not continue to increase and may actually decrease with increasing dose. Confirming this, Zhang et al. (1996) statistically analysed seven experiments and found a linear relationship between log dose and performance in broiler chicks. Such an effect was also reported more recently in layers (Pirgozliev et al., 2010) and broilers (Francesch et al., 2012; Mendes et al., 2013). It could be that with increasing dose, the benefits of additional cell wall degradation becomes compromised by the subsequent production of mono-saccharides. In support of such a hypothesis, Damen et al. (2012) showed that the in vitro molecular size reducing ability of some NSPases is dependent on dose and time.

Mannanoligosaccharides (MOS) have been suggested to have positive immune-modulating effects in broilers aged 14 to $22 \mathrm{~d}$, (Yitbarek et al., 2012), as have other oligosaccharides in humans, pigs, rats and mice (Seifert and Watz, 2007). Similarly, mannanase has been shown to modulate immunity ( $\mathrm{Li}$ et al., 2010) and positively affect performance (Zou et al., 2006) in broilers perhaps through production of MOS in situ. However care must be taken when reviewing the literature since in many cases the positive effects of MOS are demonstrated with material that is derived from yeast (Xiao et al., 2012; Yitbarek., 2012) which are not the same as those derived from cereals. Regardless, application of very high dosages of mannanase may mute the benefit if it results in MOS of too small a molecular weight to be effective Zou et al. (2006).

\section{ENZYMES AND INTESTINAL MICROBIOTA}

As already described, NSPs in cereals may 'cage' nutrients within cells and may also exert an anti-nutritional effect, through an increase in viscosity. Together, these may decrease digestibility of nutrients but may also cause the proliferation of adverse microflora, possibly due to a slowing of digesta transit but also by increasing the level of undigested nutrients available for such microflora. This topic has been thoroughly reviewed by Bedford and Cowieson (2012) and only a brief review shall be given here. Highly viscous barley and rye based diets can be improved using an antibiotic (Moran and McGinnis, 1968; MacAuliffe et al., 1976) which suggests that the detrimental effect of these cereals is partly attributable to proliferation of pathogenic bacteria. It follows that the use of an NSPase to target viscosity may reduce the prevalence of such bacterial species which are in process of being identified (Fuller, 1997; Apajalahti et al., 2004). Choct et al. (1996) showed that as viscosity was reduced in the small intestine with the use of an enzyme, VFA production also decreased, suggesting decreased fermentation in the ileum whereas caecal fermentation was markedly increased. The reduction of fermentation in the ileum was presumed to be that of starch and protein, which is clearly not beneficial as it represents lost nutrients for the host and may even produce an unfavourable microflora. The increment in cecal fermentation was likely a result of influx of xylooligosaccharides which produces VFAs and energy from otherwise indigestible substrates and often leads to a healthier microflora. Recently, Cowieson and Masey O'Neill (2013) demonstrated that with the use of xylanase, broiler cecal temperature increases, suggesting an increase in fibre fermentation. Critically, cecal temperature followed 
bird performance; when temperature was increased, overall performance was improved. In summary, this suggests nutrient digestion should be enhanced at the ileum and beneficial fermentation of fibre should be encouraged in the caeca.

Murphy et al. (2005) have shown that xylanases can improve gastric digestion of nutrients, particularly starch. Interestingly, scanning electron micrographs taken of ground corn incubated at $\mathrm{pH} 6$ with and without xylanase (Masey O'Neill unpub, Figure 1) clearly show that the enzyme appears to have de-anchored starch from the cell wall material. Given the neutral/marginally acidic $\mathrm{pH}$ optima of most commercial NSP'ases, the 'de-caging effect' likely will not take place in the gastric phase where $\mathrm{pH}$ conditions probably limit the ability of the enzyme to function, but could take place in the crop and small intestine where favourable conditions exist. This is perhaps further reason not to rely entirely on specific in vitro measurements of digestibility to predict animal performance.

It is possible that the mechanism of action of xylanase is, at least partially, indirect. It has long been understood that supplemented enzymes will release oligosaccharides from fibre for fermentation and that these oligosaccharides themselves may be beneficial. For example, Courtin et al., (2008) showed that feeding wheat bran xylooligosaccharides, derived in vitro using a xylanase, to broilers resulted in the same performance effect as feeding a xylanase directly. Furthermore, in various species the fermentation of such fibre may exert systemic, hormonal effects on the gastric phase. For example, Goodlad et al. (1987) suggested that increased colonic fermentation in rats induced the release of Peptide YY (PYY), which leads to increased gastric retention time. This is thought to lead to increased gastric digestion of all nutrients, including protein. The release of PYY in response to xylanase has been shown in initial experiments with broilers (Singh et al., 2012).

Interestingly, the provision of oligosaccharides to the caeca and large intestine may be a process that should be carefully timed and considered. Biggs et al. (2007) showed

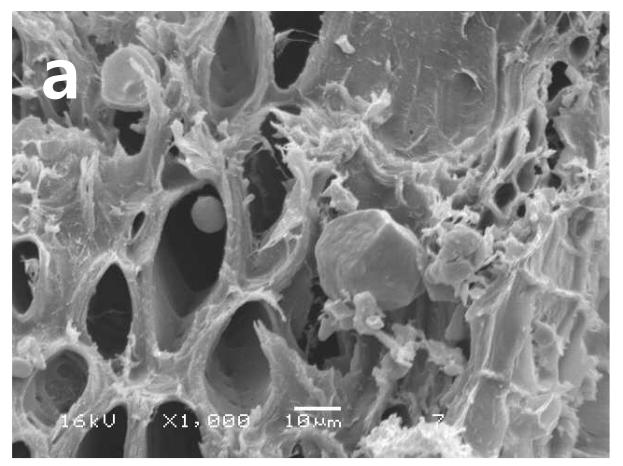

that some oligosaccharides actually reduced the AME of a corn soy diet fed to 3 to 4 d-old broiler chicks whereas others did not. These effects were apparent for amino acid digestibility as well. In most cases, at 3-4 d of age, the high oligosaccharide doses resulted in poorer digestibilities than the basal diet. As the birds aged, all oligosaccharide supplemented diets resulted in better performance than the basal but those that had reduced performance at 3-4 $\mathrm{d}$ of age took much longer before the net effects were beneficial. This is interesting as it suggests that provision of too many or the wrong type of oligosaccharides early in the life of an animal may have dramatic and detrimental effects on microflora but that eventually, as the population stabilises, provision of oligosaccharides is ultimately become beneficial.

If this mechanism is effective, the effect will not be limited to viscous cereal based diets, but will be applicable wherever there is substrate able to be enzymatically converted to oligosaccharides. For example, maize contains appreciable amounts of arabinoxylan which could be converted in vivo to arabinoxylo-oligosaccharide (AXOS) using a xylanase. If that is the case, then a suite of accessory activities are not necessary. However, this is not to say that if there is substrate available, it should all be targeted for digestion using NSPases as some oligosaccharides may be detrimental to performance.

\section{THEORETICAL AND REALISED PROBLEMS WITH MULTI-ENZYME TRIALS}

In light of previous discussions, it is possible that a multitude of enzyme activities is unnecessary, and even has the potential to be detrimental. It is nevertheless argued by some that there is, without doubt, experimental data showing multi-enzymes to be effective. Indeed, in the past two decades a growing body of literature illustrating the efficiacy of multi-component products has become available. It is, therefore, necessary to critically analyse these experiments. By discussing an example that is

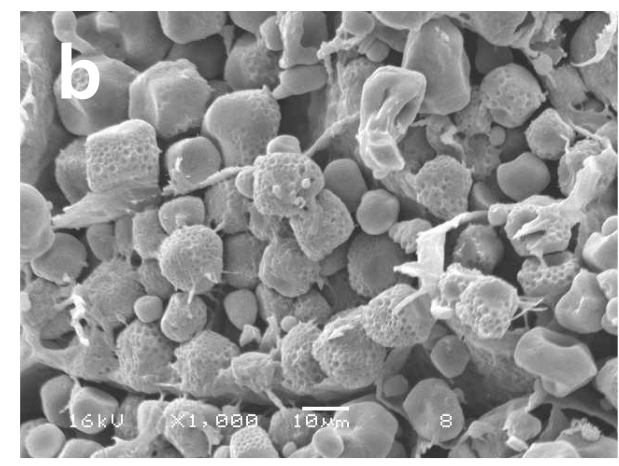

Figure 1. Ground maize incubated with a solution including (a) or excluding (b) xylanase (Econase XT, AB Vista Feed Ingredients, Marlborough, Wiltshire, UK). 
representative of the general methodology used to test the efficacy of multi-enzymes, the recurring problems seen in such trials will be highlighted.

Slominski (2000) presented results from several experiments identifying 'a new generation of enzymes for animal feeds'. The relatively successful application of single enzyme preparations is recognized, in particular the use of xylanase, phytase, or glucanase. However, it was suggested that multi-enzyme systems may provide further benefit in disrupting the cell wall and solubilising NSPs due to its complexity in component NSP. The author presented data in support of this idea, and it was concluded that a blend of enzymes could increase nutritional value of feedstuffs compared to single enzyme supplementation. The problem lies in the experimental design used to compare multi-enzymes to single enzymes. In a broiler chicken trial, one group of birds were supplemented with a combination of enzymes called Enzyme A (xylanase and $\beta$-glucanase), a second group with a multi-enzyme called Enzyme B and a control group with no enzyme. Enzyme B contained xylanase and $\beta$-glucanase as well as a variety of other enzyme activities, none of which were specified. No analyses of activities in either preparation were given, so it is unknown whether enzyme A or B contained the broadest range of activities. The enzymes were supplemented in diets low in energy, protein and available $\mathrm{P}$.

There are several points to be made here. Firstly and possibly most importantly, there was no information on the actual type or levels of the enzymes present in either product. Also, there was no comparison of a multicomponent product enzyme with a mono-component as both products contained several activities. Although enzyme $\mathrm{B}$ was better than $\mathrm{A}$ in terms of bird performance, it was not clear whether the xylanase and glucanase components of B were the same as those in A. Different NSP'ases produce different oligosaccharides, with potentially different physiological effects. Furthermore, there was no evidence the components of A were optimally dosed which is a prerequisite before any conclusion of the benefits of multiple enzyme activities can be drawn. It follows that, whatever the additional activities are, it has not been shown that a single enzyme with the same activity as that in a multicomponent product would not be equally effective, or indeed better. Romero et al. (2013) describe a series of experiments where two enzyme treatments were compared, XA (xylanase and amylase) and PXA (xylanase, amylase, protease). In many of the amino acid digestibilities the PXA treatment increased digestibility beyond the control or XA treatments. This compares whether or not enzyme preparation one is better than preparation two and suggests that PXA improves AA digestibility. However, it does not allow any conclusion on the addition of protease as the xylanases used in each treatment were different and dose was decreased with the addition of protease. This is disappointing for those interested in understanding the action of proteases. In order to show that a multi-enzyme is the best option, all of its constituent activities would need to be identified and compared to single enzymes with those activities, alone and in all possible combinations. If it outperformed all of the other combinations then it could be considered the most effective enzyme product. Identification of all the additional activities is often impractical. However, suppose that enzyme B has just one additional enzyme activity; for a full comparison, 6 further enzyme treatments would be needed, as well as a control treatment with no enzyme (Table 3). As the number of activities increases, the number of treatments needed for comparison rapidly increases, as given by:

$$
\mathrm{n} !=\mathrm{p}
$$

Where, $\mathrm{n}$ is the number of activities in the multi-enzyme and $p$ is the number of different enzyme treatments that are needed for a full comparison with the multi-enzyme. When $\mathrm{n}=7$, for example, $\mathrm{p}=5,040$. This is not an unrealistic number of activities for a multi-enzyme to have; Omogbenigun et al. (2004) for example, used enzyme preparations with up to ten activities - but only tested four treatments in the trial. On top of p, control treatments are needed as well as the treatment containing the multienzyme itself. Clearly, fully assessing the efficacy of multienzymes quickly becomes impractical.

Despite this theoretical difficulty in conducting a complete comparison, it may be argued that it is unimportant to identify exactly which activities are causal, provided that performance is improved. Indeed, a comparison of diets with a multi-enzyme product to other diets with single enzymes typically fed to broilers, as well as common combinations, may well suffice to show that the multi-enzyme was more effective. The enzyme with the most widespread use is phytase, with xylanases also being fed frequently. The problem here is that, in many trials, the comparison has simply not been made. In particular, phytase is frequently neglected in NSP'ase trials, which is

Table 3. Hypothetical experimental treatment design, as discussed

\begin{tabular}{ll}
\hline Treatment & \multicolumn{1}{c}{ Enzyme activity } \\
\hline 1 & $\begin{array}{c}\text { Enzyme B - known to contain xylanase, glucanase } \\
\text { and protease activity } \\
2\end{array}$ \\
3 & Xylanase \\
4 & Glucanase \\
5 & Protease \\
6 & Xylanase and glucanase \\
7 & Xylanase and protease \\
Control & Glucanase and protease \\
\hline
\end{tabular}


surprising given its almost ubiquitous commercial supplementation. In light of this, we might expect the gains associated with the multi-enzyme, or indeed single enzyme, to be lower if a phytase is included, as performance is improved by the phytase and thus there is subsequently less capacity for further enzyme supplementation to be useful. Cowieson et al. (2010) show that as the undigested fraction of amino acids decreases, so does the efficacy of enzyme supplementation. This explains why the use of two enzymes in combination will likely provoke a lesser response than might be predicted from the responses when the enzymes are used alone, because the undigested fraction is reduced by the first enzyme. As most commercial feeds include phytase, this should be an important consideration when evaluating the use of multi-enzymes, and could be experimentally tested with relative ease; an additional treatment with both phytase and the multi-enzyme could be compared to the multi-enzyme alone. Unfortunately, many studies fail to add this comparison although this approach does appear to becoming more common (Woyengo et al., 2010; Walk et al., 2011; Yanez et al., 2011).

Interestingly, in the limited number of studies in which a more complete comparison has been made, it is not usually the enzyme with the greatest number of activities that results in the best performance. Kalmendal and Tauson (2012) studied the effects of a xylanase and protease supplemented both individually and in combination to broilers fed wheat-soybean meal-based diets. They found that, although individually both xylanase and protease improved performance, no further improvement was seen when the enzymes were supplemented together in any growth parameters (BW, FI, or FCR). Walk et al. (2011) measured the effects of dietary enzymes on performance of broilers exposed to a live coccidia oocyst vaccine and fed a diet based on maize and soybean meal. It was found that supplementing phytase, protease or xylanase to the negative control diet lead to the same improvement in FCR as when phytase and protease, phytase and xylanase, or phytase, protease and xylanase were supplemented together. The only combination of enzymes that resulted in a further improvement in performance was phytase and xylanase. Cowieson et al. (2010) published results on the interactions between xylanase and glucanase in maize-soy-based diets in broilers, including supplementation at different levels. It was found that xylanase and glucanase alone each improved feed/gain, though combining xylanase and glucanase resulted in no further improvement. Other growth parameters were unaffected by enzyme addition. Finally, Sultan et al. (2011) studied the effects of xylanase, phytase, and protease singularly and in all combinations on the ileal protein and starch digestibility of broilers fed sorghum based diets. Supplementation of phytase was the only single enzyme to improve protein digestibility compared to the control. No combination of enzymes gave any further improvement beyond phytase.

\section{ASSAYING ENZYME PRODUCTS}

It is reasonable for a feed producer to want to assay for an ingredient once added to a feed, to check that the product is present and active. As an industry, we are becoming so confident in the stability of enzymes that often, their in-feed activity is not reported and this is a key shortcoming in a large proportion of literature on the topic. Commercially, this is important and particularly where stability is an issue, in-feed recovery may predict performance (Silversides and Bedford, 1999). Often, enzymes products will have an overage, to comply with shelf life claims and to allow for between lab assay variation. Esteve-Garcia (1997) reported recoveries of a xylanase in-feed to be, on average, $222 \%$ of the expected dose in un-pelleted barley based starter diet and $150 \%$ in an un-pelleted wheat starter diet. This highlights two issues. Presumably some of this overage comes from endogenous enzyme activity within the grain. Therefore, laboratories should use a method which only detects the exogenous product and not that of cereal or gut microflora origin, maybe an enzyme linked immunosorbant assay (ELISA) to avoid any over-estimation. However, often where more enzyme is recovered than was added, that difference, or 'background' may not be as effective in improving performance (Annison, 1991). It is also likely that those background enzymes are not thermostable and this is probably cereal dependant (Esteve Garcia et al., 1997). Secondarily, there is potential for overage to suggest one enzyme is needed at a lesser dose than another when in fact they are equivalent, or to conceal poor thermostability. However, in the aforementioned trial, thermostability was good, with on average around 93\% recovery between mash and pellet feed although the pellet temperature was only 65 degrees C (Esteve-Garcia et al., 1997).

The question also arises as to whether enzyme products are stable in the digestive tract and whether they survive acidic conditions and endogenous animal proteases. Several authors have reported the ability to recover exogenous xylanases from the digesta of broilers (Danicke et al., 1997; Silva and Smithard 2002) and pigs (Inborr et al., 1999). Inborr et al. (1999) also suggest that to best understand the activity of enzyme within the tract, the method used should employ conditions similar to those in the tract. Of course, the $\mathrm{pH}$, temperature and substrate (Sabatier and Fish, 1996) will affect the units recovered but exogenous enzymes should have as high an activity as possible at the relevant $\mathrm{pH}$ and temperature conditions of the intestinal tract (Selle and Ravindran, 2007). However, Silva and Smithard (2002) suggest that the best evidence of presence of an enzyme, which is not fraught with assay difficulties, is its efficacy - 
for example, in vivo viscosity reduction. However, this is not always a reliable predictor of improved growth performance. Choct et al. (2004) reported growth and feed conversion benefits of three different xylanase products in wheat based diets despite one of the products increasing jejunal and ileal viscosity relative to the control. Others have suggested that even when the enzyme is not recoverable, its effects on performance may still be measured (Inborr and Bedford, 1994; Sabatier and Fish, 1996; Bedford et al., 2001) which is possibly the best test of a product and comparison between products. Thus, number of units in the raw product alone are insufficient to determine performance of that product.

\section{CONCLUSION}

Until a definitive study is published to show that all components of a multi-carbohydrase enzyme are necessary for optimum benefit, there is no evidence to support their use over a single-component enzyme. However, in stating 'single-component' it must be recognised that many such products have ancillary side activities and thus interpretation of results should be treated with caution. For the benefit of all interested parties, there should be standardisation in the way in which enzyme products are described in scientific literature.

\section{REFERENCES}

Aftab, U. 2012. Exogenous carbohydrase in corn-soy diets for broilers. World's Poult. Sci. J. 68:447-464.

Angkanaporn, K., M. Choct, W. L. Bryden, and E. F. Annison. 1994. Effects of wheat pentosans on endogenous amino acid losses in chickens. J. Sci. Food Agric. 66:399-404.

Annison, G. 1991. Relationship between the levels of soluble non starch polysaccharides and the apparent metabolisable energy of wheats assayed in broiler chickens. J. Agric. Food Chem. 39:1252-1256.

Annison, G. 1992. Commercial enzyme supplementation of wheatbased diets raises ileal glycanase activities and improves apparent metabolisable energy, starch and pentosan digestibilities in broiler chickens. Anim. Feed Sci. Technol. 38:105-121

Annison, G. and M. Choct. 1991. Anti-nutritive activities of cereal non-starch polysaccharides in broiler diets and strategies minimizing their effects. World's Poult. Sci. J. 47:232-242.

Antoniou, T., R. R. Marquardt, and P. E. Cansfield. 1981. Isolation, partial characterisation and antinutritional activity of a factor (pentosans) in rye grain. J. Agric. Food Chem. 29:1240-1247.

Apajalahti, J., A. Kettunen, and H. Graham. 2004. Characteristics of the gastro-intestinal microbial communities, with special reference to the chicken. World's Poult. Sci. 60:223-232.

Arscott, G. H. and R. J. Rose. 1960. Use of barley in highefficiency broiler rations. 4. Influence of amylolytic enzymes on efficiency of utilization, water consumption and litter condition. Poult. Sci. 39:93-95.

Bedford, M. R., H. L. Classen, and G. L. Campbell. 1991. The effect of pelleting, salt and pentosanase on the viscosity of intestinal contents and the performance of broilers fed rye. Poult. Sci. 70:1571-1577.

Bedford, M. R. and H. L. Classen. 1992. Reduction of intestinal viscosity through manipulation of dietary rye and pentosanase concentration is effected through changes in the carbohydrate composition of the intestinal aqueous phase and results in improved growth rate and food conversion efficiency of broiler chicks. J. Nutr. 122:560-569.

Bedford, M. R., F. G. Silversides, and W. D. Cowan. 2001. Process stability and methods of detection of feed enzymes in complete diets. In: Enzymes in farm animal nutrition (Ed. M. R. Bedford and G. G. Partridge). CABI, Oxford, UK. pp. 377-388.

Bedford, M. R. and A. J. Cowieson. 2012. Exogenous enzymes and their effects on intestinal microbiology. Anim. Feed Sci. Technol. 173:76-85.

Biggs, P., C. M. Parsons, and G. C. Fahey. 2007. The effects of several oligosaccharides on growth performance, nutrient digestibilities, and cecal microbial populations in young chicks. Poult. Sci. 86:2327-2336.

Burnett, G. S. 1966. Studies of viscosity as the probable factor involved in the improvement of certain barleys for chickens by enzyme supplementation. Br. Poult. Sci. 7:55-75.

Burton, R. A. and G. B. Fincher. 2009. (1,3:1,4)- $\{\beta\}$-D-glucans in cell walls of the poaceae, lower plants and funghi: a tale of two linkages. Mol. Plant 2:873-882.

Cengiz, O., J. B. Hess, and S. F. Bilgili. 2012. Feed enzyme supplementation does not ameliorate foot pad dermatitis in broiler chickens fed on a corn-soyabean diet. Br. Poult. Sci. 53: 401-407.

Chesson, A. 1987. Supplementary enzymes to improve the utilization of pig and poultry diets. Rec. Adv. Anim. Nutr. 6: 71-89.

Choct, M. 1997. Feed non-starch polysaccharides: chemical structures and nutritional significance. Feed Milling International, June Issue: 13-26.

Choct, M. 1999. Effects of commercial enzymes on wet droppings in four strains of layers fed a barley-based diet. Proc. Aust. Poult. Sci. Sym., 11:89-92.

Choct, M. and G. Annison. 1990. Anti-nutritive activity of wheat pentosans in broiler diets. Br. Poult. Sci. 31:811-821

Choct, M., R. J. Hughes, J. Wang, M. R. Bedford, A. J. Morgan, and G. Annison. 1996. Increased small intestine fermentation is partly responsible for the anti-nutritive activity of non-starch polysaccharides in chickens. Br. Poult. Sci. 37:609-621.

Choct, M., R. J. Hughes, and M. R. Bedford. 1999. Effects of a xylanase on individual bird variation, starch digestion throughout the intestine, and ileal and caecal volatile fatty acid production in chickens fed wheat. Br. Poult. Sci. 40:419-422.

Choct, M., A. Kocher, D. L. E. Waters, D. Pettersson, and G. Ross. 2004. A comparison of three xylanases on the nutritive value of two wheats for broiler chickens. Br. J. Nutr. 92:53-61.

Clickner, F. H. and E. H. Follwell. 1926. Application of 'Protozyme' (Aspergillus orizae) to poultry feeding. Poult. Sci. 5:241-247.

Courtin, C. M., W. F. Broekaert, K. Swennen, O. Lescroart, O. 
Onagbesan, J. Buyse, E. Decuypere, T. van de Wiele, M. Marzorati, W. Verstraete, and G. Huyghebaert. 2008. Dietary inclusion of wheat bran arabinooligosaccharides induces benefical nutritional effects in chickens. Cereal Chem. 85: 607-613.

Cowan, D., D. R. Pettersson, and G. M. Ross. 1999. Investigations into the effect of xylanases and pectinases on broilers performance in sorghum based diets with low levels of wheat. Proc. Aust. Poult. Sci. Sym. 11:112-115.

Cowieson, A. J., M. R. Bedford, and V. Ravindran. 2010. Interactions between xylanase and glucanase in maize-soybased diets for broilers. Br. Poult. Sci. 51:246-257.

Cowieson, A. J. and H. V. Masey O'Neill. 2013. Effects of exogenous xylanase on performance, nutrients digestibility and caecal thermal profiles of broilers given wheat based diets. Br. Poult. Sci. 54:346-354.

Damen, B., A. Pollet, E. Dornez, W. F. Broekaert, I. Van Haesendonck, I. Trogh, F. Arnaut, J. A. Delcour, and C. M. Courtin. 2012. Xylanase-mediated in situ production of arabinoxylan oligosaccharides with prebiotic potential in whole mean breads and breads enriched with arabinoxylan rich materials. Food Chem. 131:111-118.

Danicke, S., O. Simon, H. Jeroch, and M. R. Bedford. 1997. Interactions between dietary fat type and xylanase supplementation when rye-based diets are fed to broiler chickens. 1. Physiochemical chime features. Br. Poult. Sci. 38:537-545.

Esteve-Garcia, E., J. Brufau, A. Perez-Vendrell, A. Miquel, and K. Duven. 1997. Bioefficacy of enzyme preparations containing $\beta$-glucanase and xylanase activities in broiler diets based on barley or wheat in combination with flavomycin. Poult. Sci. 76:1728-1737.

Francesch, M., A. M. Perez-Vendrell, and J. Broz. 2012. Effects of a mono-component endo-xylanase supplementation on the nutritive value of wheat-based broiler diets. Br. Poult. Sci. 53:809-816.

Fry, R. E., J. B. Allred, L. S. Jensen, and J. McGinnis. 1958. Influence of enzyme supplementation and water treatment on the nutritional value of different grains for poults. Poult. Sci. 37:372-375.

Fuller, R. 1997. Modification of the intestinal microflora using probiotics and prebiotics. Scand. J. Gastroenterol. (Suppl.) 222:28-31.

Gohl, B., S. Alden, K. Elwinger, and S. Thomke. 1978. Influence of $\beta$-glucanase on feeding value of barley for poultry and moisture contents of excreta. Br. Poult. Sci. 19:41-47.

Goodlad, R. A., W. Lenton, M. Ghatei, T. E. Adrian, S. R. Bloom, and N. A. Wright. 1987. Proliferative effects of 'fibre' on the intestinal epithelium: relationship to gastrin, enteroglucagon and PYY. Gut 28:221-226.

Grootwassink, J. W. D., G. L. Campbell, and H. L. Classen. 1989. Fractionation of crude pentosanase (arabinoxylanase) for improvement of the nutritional value of rye diets for broiler chickens. J. Sci. Food Agric. 46:289-300.

Guais, O., G. Borderies, C. Pichereaux, M. Maestracci, V. Neugnot, M. Rossignol, and J. M. Francois. 2008. Proteomics analysis of 'Rovabio Excel', a secreted protein cocktail from the filamentous fungus Penicillium funiculosum grown under industrial process fermentation. J. Ind. Microbiol. Biotechnol. 35:1659-1668.

Hervey, G. W. 1925. A nutritional study upon a fungus enzyme. Science 62:247.

Hesselman, K., K. Elwinger, M. Nilsson, and S. Thomke. 1981. The effect of $\beta$-glucanase supplementation, stage of ripeness and storage treatment of barley in diets fed to broiler chickens. Poult. Sci. 60:2664-2671.

Hesselman, K., K. Elwinger, and S. Thomke. 1982. Influence of increasing levels of $\beta$-glucanase on the productive value of barley diets for broiler chickens. Anim. Feed Sci. Technol. 7:351-358.

Hesselman, K. and P. Aman. 1986. The effect of B-glucanase on the utilization of starch and nitrogen by broiler chickens fed on barley of low- or high- viscosity. Anim. Feed Sci. Technol. 15: 83-93.

Inboor, J. and M. R. Bedford. 1994. Stability of feed enzymes to steam pelleting during feed processing. Anim. Feed Sci. Technol. 46:179-196.

Inborr, J., J. Puhakka., J. G. M. Bakker, and J. van der Meulen. 1999. $\beta$-Glucanase and $x y$;lanase activities in stomach and ileum of groeing pigs fed wheat bran based diets with and without enzyme treatment. Archiv. Fur. Tierernaehrung 52:263-274.

Jensen, L. S., R. E. Fry, J. B. Allred, and J. McGinnis. 1957. Improvement in the nutritional value of barley for chicks by enzyme supplementation. Poult. Sci. 36:919-921.

Józefiak, D., A. Ptak, S. Kaczmarek, P. Maçkowiak, M. Sassek, and B. A. Slominski. 2010. Multi-carbohydrase and phytase supplementation improves growth performance and liver insulin receptor sensitivity in broiler chickens fed diets containing full-fat rapeseed. Poult. Sci. 89:1939-1946.

Kalmendal, R. and R. Tauson. 2012. Effects of a xylanase and protease, individually or in combination, and an ionophore coccidiostat on performance, nutrient utilization, and intestinal morphology in broiler chickens fed a wheat-soybean mealbased diet. Poult. Sci. 91:1387-1393.

Li, Y., X, Chen, Y. Chen, Z. Li, and Y. Cao. 2010. Effects of $\beta$ mannanase expressed by Pichia pastoris in corn-soybean meal diets on broiler performance, nutrient digestibility, energy utilization and immunoglobulin levels. Anim. Feed Sci. Technol. 159:59-67.

MacAuliffe, T., A. Pietraszek, and J. McGinnis. 1976. Variable rachitogenic effect of grain and alleviation by extraction or supplementation with vitamin D, fat and antibiotics. Poult. Sci. 55:2142-2147.

Macauliffe, T. and J. McGinnis. 1971. Effect of antibiotic supplements to diets containing rye on chick growth. Poult. Sci. 50:1130-1134.

Marquardt, R. R., A. T. Ward, and R. Misir. 1979. The retention of nutrients by chicks fed rye diets supplemented with amino acids and penicillin. Poult. Sci. 58:631-640.

Masey O'Neill, H. V, M. R. Bedford, H. Graham, and A. Kumar. 2012a. Comparing a thermotolerant xylanase with a multienzyme blend in wheat-based broiler diets. Proc. Aust. Poult. Sci. Sym. 23:280-282.

Masey O'Neill, H. V., N. Lui, J. P. Wang, A. Diallo, and S. Hill. $2012 \mathrm{~b}$. Effect of xylanase on performance and apparent 
metabolisable energy in starter broilers fed diets containing one maize variety harvested in different regions of China. Asian-Aust. J. Anim. Sci. 25:515-523.

Mendes, A. R., T. Ribiero, B. A. Correia, P. Bule, B. Macas, L. Falcao, J. P. B. Freire, L. M. A. Ferreira, C. M. G. A. Fontes, and M. M. Lordelo. 2013. Low doses of exogenous xylanase improve the nutritive value of triticale based diets for broilers. J. Appl. Poult. Res. 22:92-99.

Meng, X., B. A. Slominski, C. M. Nyachoti, R. G. Campbell, and W. Guenter. 2005. Degradation of cell wall polysaccharides by combinations of carbohydrase enzymes and their effect on nutrient utilization and broiler chicken performance. Poult. Sci. 84:37-47.

Moran, E. T. and McGinnis. 1968. Growth of chicks and turkey poults fed western barley and corn- based rations: Effect of autoclaving on supplemental enzyme requirement and assymetry of antibiotic response between grains. Poult. Sci. 47:152-158.

Moran, E. T., S. P. Lall, and J. D. Summers. 1969. The feeding value of rye for the growing chick; Effect of enzyme supplements, antibiotics, autoclaving and geographical area of production. Poult. Sci. 48:939-949.

Murphy, T. C., M. R. Bedford, and K. McCracken. 2005. Xylanase action on non-starch polysaccharides along the digestive tract of broilers. Br. Poult. Abs. 1.38.

Omogbenigun, F. O., C. M. Nyachoti, and B. A. Slominski. 2004. Dietary supplementation with multienzyme preparations improves nutrient utilization and growth performance in weaned pigs. J. Anim. Sci. 82:1053-1061.

Persia, M. E., B. A. Dehority, and M. S. Lilburn. 2002. The effects of enzyme supplementation of corn- and wheat-based diets on nutrient digestion and cecal microbial populations in turkeys. J. Appl. Poult. Res. 11:134-145.

Persson, I., F. Tjerneld, and B. Hahn-Hagerdal. 1991. Fungal cellulolytic enzyme production: A review. Proc. Biochem. 26:65-74.

Pettersson, P. and P. Aman. 1988. Effects of enzyme supplementation of diets based on wheat, rye, or triticale on their productive value for broiler chickens. Anim. Feed Sci. Technol. 20:313-324.

Pirgozliev, V., M. R. Bedford, and T. Acamovic. 2010. Effect of dietary xylanase on energy, amino acid and mineral metabolism, and egg production and quality in laying hens. Br. Poult. Sci. 51:639-647.

Polizeli, M. L. T. M., A. C. S. Rizzatti, R. Monti, H. F. Terenzi, J. A. Jorge, and D. S. Amorim. 2005. Xylanases from fungi: properties and industrial applications. Appl. Microbiol. Biotechnol. 67:577-591.

Romero, L., C. M. Parsons, P. L. Utterback, P. W. Plumstead, and R. Ravindran. 2013. Comparative effects of dietary carbohydrases without or with protease on the ileal digestibility of energy and amino acids and AMEn in young broilers. Anim. Feed Sci. Technol. 181:35-44.

Rose, R. J. and G. H. Arscott. 1962. Use of barley in highefficiency broiler rations. 5. Further studies on the use of enzymes soaking and pelleting barley for chicks. Poult. Sci. 41:124-130.

Sabatier, A. M. and N. M. Fish. 1996. Methods for analysis of feed enzymes: methodological problems? J. Appl. Poult. Sci. 5:408413.

Saulnier, L, F. Guillon, and A-L. Chateigner-Boutin. 2012. Cell wall deposition and metabolism in wheat grain. J. Cereal Sci. 56:91-108.

Schaeffer, P. 1969. Sporulation and the production of antibiotics, exoenzymes and exotoxins. Bacteriol. Rev. 33:48-71.

Schutte, J. B. 1990. Nutritional implications and metabolizable energy value of D- xylose and L-arabinose in chicks. Poult. Sci. 69:1724-1730.

Seifert, S. and B. Watzl. 2007. Inulin and oligofructose: Review of experimental data on immune modulation. J. Nutr. 137:2563S2567S.

Selle, P. H. and V. Ravindran. 2007. Microbial phytase in poultry nutrition. Anim. Feed Sci. Technol. 135:1-41.

Silva, S. S. P. and R. R. Smithard. 2002. Effect of enzyme supplementation of a rye-based diet on xylanases activity in the small intestine of broilers, on intestinal crypt cell proliferation and on nutrient digestibility and the growth performance of birds. Br. Poult. Sci. 43:274-282.

Silversides, F. G. and M. R. Bedford. 1999. Effect of pelleting temperature on the recovery and efficacy of a xylanase enzyme in wheat-based diets. Poult. Sci. 78:1184-1190.

Singh, A., H. V. Masey O'Neill, T. K. Ghosh, M. R. Bedford, and S. Haldar. 2012. Effects of xylanase supplementation on performance, total volatile fatty acids and selected bacterial populations in caeca, metabolic indices and peptide YY concentrations in serum of broiler chickens fed energy restricted maize-soybean based diets. Anim. Feed Sci. Technol. 177:194-203.

Slominski, B. A. 2000. A new generation of enzymes for animal feeds. Proc. 21st Western Nutrition Conference, Winnipeg, Manitoba, Canada.

Slominski, B. A. 2011. Recent advances in research on enzymes for poultry diets. Poult. Sci. 90:2013-2023.

Somerville, C., S. Bauer, G. Brininstool, M. Facette, T. Hamann, J. Milne, E. Osborne, A. Paredez, S. Persson, T. Raab, S. Vorwerk, and H. Youngs. 2004. Toward a systems approach to understanding plant cell walls. Science 306:2206-2211.

Sultan, A., Y. T. Gan, X. Li, D. Zhang, and W. L. Bryden. 2011. Dietary enzyme combinations improve sorghum ileal protein and starch digestibility during the broiler starter phase. Proc. Aust. Poult. Sci. Sym. 22:82.

Thacker, P. A., G. L. Campbell, and J. Grootwassink. 1991. The effect of enyme supplementation on the nutritive value of ryebased diets for swine. Can. J. Anim. Sci. 71:489-496.

Theander, O., E. Westerlund, P. Aman, and H. Graham. 1989. Plant cell walls and monogastric diets. Anim. Feed Sci. Technol. 23:205-225.

Walk, C. L., A. J. Cowieson, J. C. Remus, C. L. Novak, and A. P. McElroy. 2011. Effects of dietary enzymes on performance and intestinal goblet cell number of broilers exposed to a live coccidia oocyst vaccine. Poult. Sci. 90:91-98.

Walsh, M. C., P. A. Geraert, R. Maillard, J. Kluess, and P. G. Lawlor. 2012. The effect of a non-starch polysaccharidehydrolysing enzyme (Rovabio-R Excel) on feed intake and body condition of sows during lactation and on progeny growth performance. Animal 6:1627-1633. 
White, W. B., H. R. Bird, M. L. Sunde, N. Prentice, W. C. Burger, and J. A. Marlett. 1981. The viscosity interaction of barely $\beta$ glucan with trichoderma viride cellulase in the chick intestine. 60:1043-1048.

White, W. B., H. R. Bird, M. L. Sunde, J. A. Marlett, N. Prentice, and W.C. Burger. 1983. Viscosity of $\beta$-D-glucan as a factor in the enzymatic improvement of barley for chicks. Poult. Sci. 62:853-862.

Woyengo, T. A., B. A. Slominski, and R. O. Jones. 2010. Growth performance and nutrient utilization of broiler chickens fed diets supplemented with phytase alone or in combination with citric acid and multicarbohydrase. Poult. Sci. 89:221-2229

Xiao, R., R. F. Power, D. Mallonee, K. Routt, L. Spangler, A. J. Pescatore, A. H. Cantor, T. Ao, J. L. Pierce, and K. A. Dawson. 2012. Effects of yeast cell wall-derived mannanoligosaccharides on jejunal gene expression in young broiler chickens. Poult. Sci. 91:1660-1669.
Yanez, J. L., E Beltranena, M. Cervantes, and R. T. Zijlstra. 2011. Effect of phytase and xylanase supplementation or particle size on nutrient digestibility of diets containing distillers dried grains with solubles cofermented from wheat and corn in ilealannulated grower pigs. J. Anim. Sci. 89:113-123.

Yitbarek, A., H. Echeverry, J. Brady, J. Hernandez-Doria, G. Camelo-Jaimes, S. Sharif, W. Guenter, J. D. House, and J. C. Rodriguez-Lecompte. 2012. Innate immune response to yeastderived carbohydrates in broiler chickens fed organic diets and challenged with Clostridium perfringens. Poult. Sci. 91:11051112

Zhang, Z., R. R. Marquardt, G. Wang, W. Guenter, G. H. Crow, Z. Han, and M. R. Bedford. 1996. A simple model for predicting the response of chicks to dietary enzyme supplementation. J. Anim. Sci. 74:394-402.

Zou, X. T., X. J. Qiao, and Z. R. Xu. 2006. Effect of $\beta$-Mannanase (Hemicell) on growth performance and immunity of broilers. Poult. Sci. 85:2176-2179. 